\title{
Machine Perfusion of Lungs
}

\section{Toshihiro Okamoto $^{1,2,3} \cdot$ Hiromichi Niikawa ${ }^{1,2} \cdot$ Kamal Ayyat $^{1,2} \cdot$ Ichiro Sakanoue $^{1,2} \cdot$ Sayf Said $^{2}$. Kenneth R. McCurry ${ }^{1,2,3}$}

Published online: 30 November 2019

(C) Springer Nature Switzerland AG 2019

\begin{abstract}
Purpose of Review The purpose of this review is to summarize the fundamentals, rationale, research topics, and clinical outcomes of ex vivo lung perfusion.

Recent Findings Since the first clinical case in 2000, the usefulness of ex vivo lung perfusion to increase the donor lung pool has been supported by much evidence. The main role of ex vivo lung perfusion is to evaluate, preserve, and treat lungs that otherwise might not be useable for transplantation. Many studies have been conducted to evaluate the optimal perfusate, flow, method of evaluation, markers of lung performance, and possible treatment strategies. Moreover, during the last decade, clinical trials have demonstrated comparable clinical outcomes to lung transplants performed with standard donors without EVLP.

Summary Ex vivo lung perfusion is an effective tool to evaluate lungs and to salvage rejected donor lungs to increase the donor lung pool.
\end{abstract}

Keywords Ex vivo lung perfusion $\cdot$ Lung transplantation $\cdot$ Lung donor

\section{Introduction}

Lung transplantation is an established treatment for advanced pulmonary disease. In spite of the use of marginal donors and donation after circulatory death (DCD) donors as well as aggressive organ donor management, the utilization of donor lungs is still limited to $20 \%$ in the USA [1]. Due to this limited lung utilization, there remains a wide gap between supply and demand for lungs resulting in significant wait-list mortality [1]. Ex vivo lung perfusion (EVLP) is an emerging technology

This article is part of the Topical Collection on Machine Preservation of the Liver

Toshihiro Okamoto

okamott@ccf.org

Kenneth R. McCurry

mccurrk@ccf.org

1 Department of Thoracic and Cardiovascular Surgery, Cleveland, USA

2 Department of Inflammation \& Immunity, Lerner Research Institute, Cleveland, USA

3 Transplant Center, Cleveland Clinic, 9500 Euclid Ave. J4-1, Cleveland, OH 44195, USA with a great potential to increase the donor lung supply. Research on EVLP components has been reported and promising clinical outcomes have been published in several clinical trials and single-center studies [2, 3••, 4-7] [35-38, 108-113]. However, the impact of EVLP to increase donor lung pool has been limited to experienced transplant centers. The purpose of this review is to summarize the current status of ex vivo lung perfusion.

\section{Fundamental Aspect of Lung Perfusion: Small Animal Lungs}

The optimal perfusate of the isolated perfused lung (IPL) model should have osmolality and oncotic pressures similar to normal blood and must also provide an energy source (e.g., glucose) and electrolytes consistent with extracellular fluid $[8,9]$ so that normal cellular processes in physiological conditions are maintained [10]. The standard temperature utilized was body temperature $\left(37^{\circ} \mathrm{C}\right)$. Much work has been published using cellular (heparinized whole blood, washed red blood cells with albumin and Krebs-Henseleit solution) or acellular (albumin and Krebs-Henseleit solution or STEEN solution) perfusates [11-16]. Fukuse et al. described 
the importance of red blood cells in Krebs-Henseleit solution in a rat model [16]. The use of red blood cells in perfusate resulted in significantly better pulmonary function than acellular perfusate during $60 \mathrm{~min}$ of perfusion. Historically, rat lung ex vivo lung perfusion had great potential to be an experimental platform for translational research despite the short perfusion time (45-60 $\mathrm{min}$ ) [13-16]. In 2014, Noda et al. reported rat lung EVLP with prolonged perfusion time ( $4 \mathrm{~h}$ ) by modifying the flow rate to $20 \%$. Normal pulmonary function was demonstrated at $2 \mathrm{~h}$ following subsequent lung transplantation [12]. Bassani et al. provided a detailed description and video of actual procedures of rat lung EVLP of 3 -h duration [11]. Ventilation was initiated only when lung temperature reached the physiological range. As with perfusion flow settings in IPL systems, target ventilation settings varied widely between protocols. Target tidal volume was 3$10 \mathrm{ml} / \mathrm{kg}$, positive end expiratory airway pressure (PEEP) was $2-5 \mathrm{cmH}_{2} \mathrm{O}$, and respiratory rate was $30-60$ breaths/ $\min [11,12,15,17]$. Ventilation protocols generally utilized a lung protective strategy to minimize lung mechanical lung injury. In contrast to other work, DeCampos et al. suggested that alveolar recruitment prior to reperfusion reduces reperfusion-induced lung injury in a rat model [13]. Pierre et al. showed the importance of gradual lung rewarming (from 20 to $37^{\circ} \mathrm{C}$ ) to reduce the lung injury [18]. To date, EVLP with small animal lungs is considered to be particularly useful in the investigation of the optimal settings of EVLP and in the evaluation of strategies and pharmacologic agents to mitigate ischemia reperfusion injury (IRI).

\section{Fundamental Aspect of Lung Perfusion: Large Animal Lungs}

Large animal lungs, especially porcine lungs, have also been used historically in research EVLP because of their resemblance to human lungs [19-21]. Furthermore, the left lung transplantation model following EVLP provides the opportunity to evaluate post-operative graft function, compared with ex vivo model [19-22]. Regarding animal models to evaluate organ preservation devices, the U.S. Food and Drug Administration (FDA) has recommended two models of reperfusion to access the severity of reperfusion injury: an ex vivo model and an in vivo model. The ex vivo model has advantages in controlled study environment and more detailed data collection. In contrast, the in vivo model allows for the whole-body immune response and real coagulation and inflammatory cascades [23]. It should be noted that the cold ischemia time $(>24 \mathrm{~h}$ ) to produce IRI in the porcine lung is generally longer than that of the human lung $(>8 \mathrm{~h})$, and caution is needed in interpreting experimental results.

\section{Roles of EVLP}

\section{Assessment}

The assessment of transplant suitability during EVLP is a synthesis of a wide range of variables and factors. Each protocol has their own criteria for judgment.

The Lund protocol claims that no additional time should be spent on the circuit if initial blood gas values, hemodynamics, and ventilator parameters and the macroscopic findings are deemed satisfactory. Blood gas analysis is the standard metric and $\mathrm{P} / \mathrm{F}$ ratio $>300 \mathrm{mmHg}$ is the gold standard for transplant suitability because the solution containing red blood cell ensures high reliability of blood gas analysis for lung transplant suitability [24]. It is important to note that the $\mathrm{P} / \mathrm{F}$ ratio varies at different $\mathrm{FiO}_{2}$ levels [25] and $\mathrm{FiO}_{2}$ of 1.0 provides the greatest predictive value to determine transplant suitability out of three $\mathrm{FiO}_{2}\left(0.21,0.4\right.$, and 1.0) [26]. $\mathrm{PaO}_{2} / \mathrm{FiO}_{2}$ ratio and airway parameters correlate in porcine lungs [27] and, therefore, following the trend of airway parameters might be useful as a complementary indicator of lung function.

The Toronto protocol requires the reconditioning perfusion process to be maintained for 3-4 h with hourly assessments before determining transplant suitability. Yeung et al. reported that blood gas analysis alone may be misleading in the evaluation for transplant suitability [28]. Therefore, assessment should include other physiological parameters including the trend of airway parameters as well as other visual findings.

Since the aim of the Organ Care System (OCS) protocol is to transport organs on the OCS portable machine, optimal perfusion time has not been set. The OCS system uses blood gas analysis and physiological parameters: calculated $\mathrm{PaO}_{2} / \mathrm{FiO}_{2}$ ratio and sequential re-oxygenation test, which measure the time required to increase the blood saturation from 73 to $93 \%$ at $\mathrm{FiO}_{2}$ of 0.21 [29].

When there are concerns about disseminated, purulent secretions or bleeding in an isolated lung, then single-lung EVLP (SL-EVLP) should be considered by initiating EVLP as a single lung or clamping one side during EVLP. Clinically, both tidal volume (TV) and perfusion flow for double-lung EVLP will be reduced by half [30-32]. Our group compared physiological parameters between DL-EVLP and SL-EVLP using rejected donor lungs [33] and found that $\mathrm{PO}_{2} / \mathrm{FiO}_{2}$ ratio in SL-EVLP was significantly lower than that from the corresponding pulmonary vein in DL-EVLP (182 vs. $312 \mathrm{mmHg}$ ). This discrepancy should be considered in the evaluation of the transplant suitability in SL-EVLP.

\section{Preservation}

The Lund protocol has a minimum perfusion time of $1-2 \mathrm{~h}$. In a porcine DCD model, Erasmus et al. demonstrated that $100 \%$ cardiac output flow with perfusion for $6 \mathrm{~h}$ resulted in growing 
pulmonary edema [34]. To reduce the risk of hydrostatic pressure-induced pulmonary edema, perfusion is limited to $1 \mathrm{~h}$ if at that point lungs are acceptable for transplantation $[35,36]$. In the Toronto protocol, clinical data comparable to standard transplant group support perfusing donor lungs safely for $4 \mathrm{~h}[2,37]$. In an experimental setting, human and porcine lungs were preserved for up to $12 \mathrm{~h}[20,21]$. The mean perfusion duration of standard criteria donor lungs in the OCS system was $303 \mathrm{~min}$ (range 188-622) [38].

When Lund or Toronto type EVLP is utilized, total preservation time, which is defined as the sum of first cold ischemic time (CIT), EVLP time, and second CIT, is significantly longer than CIT of standard lung transplant $(6-8 \mathrm{~h})$. Acceptable total preservation time was $18.1 \mathrm{~h}$ (median) in Lund protocol [35], and $14.6 \mathrm{~h}$ (mean) in Toronto protocol [39••]. Hsin et al. reported that prolonged second CIT of $10 \mathrm{~h}$ had no negative effect on post-transplant pulmonary function, compared with control with second CIT of $2 \mathrm{~h}$ in a porcine lung model [40]. Cypel et al. proposed a semi-elective lung transplantation by using EVLP [41]. In contrast, several groups reported that $24 \mathrm{~h}$ of prolonged EVLP might preserve porcine lungs in Toronto protocol or OCS [42-44].

\section{Treatment}

EVLP repairs damaged lungs mainly by reducing edema and atelectasis. The high oncotic pressure of STEEN solution reduces edema while atelectasis is eliminated by alveolar recruitment. EVLP also provides a platform for treatment with medication and genetic therapies prior to transplantation. Cypel et al. demonstrated that administering a vector expressing IL-10 promoted anti-inflammatory cytokine expression and improved lung function [45]. Although pneumonia in lung donors is generally considered as a contraindication to EVLP, several reports on microbial load during EVLP have been reported. Andreasson et al. demonstrated bacterial loads decreased during EVLP with high-dose, empirical, broadspectrum, anti-microbial agents [46]. Similarly, Nakajima et al. reported that EVLP treatment of infected donor lungs reduced bronchial-alveolar lavage bacterial counts and endotoxin levels [47]. Recently, Galasso et al. showed that germicidal light-based therapies inactivate hepatitis $\mathrm{C}$ virus during $\operatorname{EVLP}[48 \bullet \cdot]$.

\section{Differences in EVLP Strategies}

\section{Perfusate: Cellular vs. Acellular}

There have been four studies comparing cellular and acellular perfusate using swine lungs in EVLP [49-52]. Two studies concluded that there was no significant difference in outcomes between cellular or acellular solutions $[49,50]$. In contrast, the other two papers reported that pulmonary edema was significantly greater in the acellular group compared with cellular $[51,52 \bullet]$. This finding is consistent with our recent publication comparing acellular and cellular EVLPs using human donor lungs with a prolonged CIT of $13.8 \mathrm{~h}[53 \bullet]$.

\section{Left Atrium}

There are two strategies for managing the left atrium during EVLP: an open left atrium (LA) or a closed LA. In the Lund and OCS protocols, the remnant of LA is opened widely, while in the Toronto protocol, LA is cannulated, and LA pressure was continuously maintained at $3-5 \mathrm{mmHg}$ during perfusion. Based on the previous report, the positive LA pressure tented open the capillaries and post-capillary venules and prevents cyclical collapse of the micro-vessels from occurring during increases in airway pressures and decreases of flow at inspiration [54]. Linacre et al. reported that maintaining a physiologic positive LA pressure $(3-5 \mathrm{mmHg}$ ) during $12 \mathrm{~h}$ lead to significantly less edema and superior lung physiology in a pig model [55].

\section{Ventilation}

All current clinical protocols require ventilation settings of tidal volume (TV) of 6-7 ml/kg and positive end expiratory pressure (PEEP) of $5 \mathrm{cmH}_{2} \mathrm{O}$ as a lung protective ventilation strategy [56]. However, Terragni et al. reported these standard ventilator settings (TV $7 \mathrm{ml} / \mathrm{kg}$, PEEP of $5 \mathrm{cmH}_{2} \mathrm{O}$, and respiratory rate 7 breaths/min) during EVLP may expose some of perfused lungs to ventilator-induced lung injury. Stress index was utilized to evaluate the rate of changes in lung compliance during tidal inflation in EVLP. They demonstrated that one group with stress index of 0.95 to 1.05 was associated with shorter mechanical ventilation length, and ICU and hospital stay than the other group, whose stress index was $>1.05$ or $<$ 0.95 [57]. Furthermore, Mehaffey et al. demonstrated that a new strategy of airway pressure release ventilation (APRV) might be protective during EVLP using a pig DCD model. They reported that the APRV strategy was significantly associated with better pulmonary function after lung transplant than controls [58•]. Aboelnazar et al. demonstrated that negative pressure ventilation reduces pulmonary injury using porcine lung EVLP [59].

\section{Others}

There are studies on other EVLP variables, including oxygenation concentration of perfusate [60], leukocyte filter [61] [62], and pump [63] in EVLP. 


\section{Research Topics in EVLP}

\section{Position}

Prone positioning has been shown to improve oxygenation in patients with lung injury in intensive care units [64]. Our group has demonstrated that prone positioning of lungs during the Lund protocol may diminish ischemia-reperfusion injury and improve lung function using pig a DCD donor model [65•]. The suggested mechanism was that ventilationperfusion matching was improved by prone positioning during EVLP. Furthermore, results of prone positioning during EVLP utilizing human donor lungs were consistent with the results of the pig model (Unpublished data in McCurry lab).

\section{Additional Parameters in Evaluation}

\section{Differential Blood Gas Analysis}

Costa et al. reported that selective pulmonary vein gases provide corroborative objective support to the findings of bronchoscopy, palpation, and visual assessment of donor lungs in lung donor evaluation [66]. This concept might be useful in the EVLP setting. In order to judge the oxygenation changes in each lung lobe during EVLP, we measure $\mathrm{pO}_{2}$ of each pulmonary vein (PV) by a direct puncture method. The value should be considered as supplemental information for evaluation for transplant suitability.

\section{P/F Difference}

The difference between two $\mathrm{PaO}_{2} / \mathrm{FiO}_{2}(\mathrm{P} / \mathrm{F})$ ratios at two different $\mathrm{FiO}_{2}$ depends on shunt fraction when utilizing Lund protocol EVLP [25]. A new concept of "P/F difference (PFD)" was defined as follows: $\mathrm{PFD}_{1-0.4}=\mathrm{P} / \mathrm{F}$ ratio at $\mathrm{FiO}_{2}$ 1.0-P/F ratio at $\mathrm{FiO}_{2}$ 0.4. Our results in Lund EVLP demonstrated that $\mathrm{PFD}_{1-0.4}$ might predict the increase in lung weight during $2 \mathrm{~h}$ of EVLP, and better identify non-suitable donor lungs with higher specificity than the $\mathrm{P} / \mathrm{F}$ ratio at $\mathrm{FiO}_{2} 1.0$ which is considered as a gold standard of evaluation for transplant suitability [26].

\section{Extravascular Lung Water Assessment}

Extravascular lung water (EVLW) content of donor lungs can change in a time-dependent fashion during EVLP. The elevated EVLW content in donor lungs can adversely affect the outcomes of lung transplant [67]. The measurement of EVLW can aid the assessment and guide the management of donor lungs. Trebbia et al. have utilized transpulmonary thermodilution for calculating EVLW index. They found that EVLW index had the highest area under the receiver-operating characteristic curve for predicting PGD in recipients compared with $\mathrm{P} / \mathrm{F}$ ratio and static lung compliance [68]. Recently, our group has described a novel technique to accurately measure EVLW using ultrasound; direct lung ultrasound evaluation (CLUE). By providing a score for each point in donor lung, and calculating a score for the whole lung and each lobe of the lung, CLUE technique can provide an accurate and non-invasive diagnostic tool for monitoring EVLW during EVLP [69]. Additionally, lung weight measurement can provide a simple way for a general quantitative assessment of EVLW. Molina and DiMaio demonstrated that lung weight was affected by visceral congestion and blood loss [70, 71]. Tagami et al. had also demonstrated a correlation between lung weight and EVLW, measured by thermodilution [72].

\section{Inflammatory cytokines, Protein Expression and Metabolic Profiles.}

Many publications reported that inflammatory cytokines in perfusate or bronchial-alveolar leverage increase during EVLP. Andreasson et al. demonstrated that IL-1 beta elevation in perfusate was a predictive biomarker of post-operative outcomes and lung injury during cellular EVLP [73]. The Toronto Group reported that protein expression and metabolomics profiles are potential markers of primary graft dysfunction in cellular EVLP [74, 75].

\section{Hemofiltration}

The hyperoncotic properties of the EVLP perfusate theoretically may decrease lung water content. Wallinder et al. have attempted control osmotic pressure of perfusate on one rejected human donor lung using Lund protocol EVLP circuit with a hemofilter incorporated. However, their results only proved the delay and unpredictability of the effect of the hemoconcentration procedure [76]. This group tested this innovative hypothesis with pig lung edema model. The results demonstrated that hemofilter during EVLP increased perfusate oncotic pressure and decreased lung weight with beneficial effects on compliance, but did not show improvement in oxygenation capacity [77].

\section{Surfactant}

Khalife and colleagues reported that surfactant attenuated lung injury during EVLP utilizing an aspiration-model with gastric acid [78]. Inch et al. tested whether an injured pig lung graft from a controlled DCD donor could be reconditioned with EVLP system by intrabronchial diluted surfactant lavage before transplantation [79]. They demonstrated that the surfactant group showed better oxygenation and lower pulmonary vascular resistance during EVLP. Recently, Nakajima et al. founded that lung lavage and surfactant replacement in EVLP led to better outcomes using pig gastric acid-induced 
lung injury model [80]. Because this innovative treatment attempt in EVLP has not yet been performed in the human lungs, further study is needed in the future.

\section{Hydrogen}

Hydrogen has been shown to have antioxidant and antiinflammatory effects and selectively reduces hydroxyl radicals. It has been demonstrated to have beneficial antioxidant effects in ischemia reperfusion injury models of the brain, heart, liver, and intestine [81]. Noda et al. reported that hydrogen inhalation attenuated the prominent pro-inflammatory change and compromised metabolic profiles in a rat EVLP model [82]. Haam et al. reported that hydrogen inhalation during EVLP improved the pulmonary function of DCD pig lungs [83].

\section{Urokinase, Tissue Plasminogen Activator, and Plasmin}

Pulmonary embolism (PE) causes low oxygenation in donor lungs, which is typically considered a contraindication to providing lungs for transplantation. $\mathrm{PE}$ is a frequent finding in organ donors [84]. Macroscopic thrombi during retrograde preservation flushing is associated with worse outcomes after lung transplantation [85]. Brown et al. reported the use of $7 \mathrm{~h}$ of EVLP to evaluate and possibly improve a pair of donor lungs with PE and poor oxygen to suitable condition for subsequent transplantation [86]. Inch et al. reported that in a pig model, adding urokinase into the perfusate during EVLP resulted in improved graft function by reducing pulmonary vascular resistance and increasing oxygenation [87]. Additionally, this group reported successful lung transplantation after donor lung reconditioning with Urokinase in EVLP [88]. Motoyama et al. demonstrated that plasmin administration in an EVLP model dissolved thrombi in the rat lungs, resulting in reconditioning of the lungs [89]. Mauchuca et al. reported the first therapeutic ex vivo thrombolysis with tissue plasminogen activator followed by clinical transplantation [90].

\section{Neutrophil Elastase Inhibitor}

Harada et al. reported that addition of a neutrophil elastase inhibitor to the perfusate reduced lung reperfusion injury using a pig EVLP model [91]. Lin et al. demonstrated similar protective effect of alpha-1-antitrypsin [92]. Charles et al. reported protective effect of adenosine $\mathrm{A} 2 \mathrm{~B}$ receptor antagonist in pig DCD model [93].

\section{Selection of Donors for EVLP}

Major indications for EVLP include the following: (1) to evaluate donor lungs of questionable pulmonary function and (2) to preserve lungs for logistics. The general pathology targets of EVLP include pulmonary edema and atelectasis. Lung weight reduction during EVLP might be limited in the Toronto protocol [51-53] but post-operative management using diuretics might control pulmonary edema. Small to moderate size of atelectasis is recruited in EVLP, while it was difficult to recruit large atelectasis (mean size of atelectasis: $75 \%$ of lower lobes) of donor lungs on EVLP, because of the difference in pulmonary compliance between the normal upper lobe and the atelectatic lower lobe [94]. Additionally, atelectatic status during cold storage has a negative impact on pulmonary function [95]. The role of EVLP in other pathologies including infection, contusion, and aspiration might be limited but ongoing studies are evaluating. Lungs from donors $>55$ years old or with a smoking or transfusion history might be perfused for the purpose of evaluation rather than treatment.

The indication for EVLP in DCD donors varies in each country $[96 \cdot \bullet$. Toronto General Hospital started to perfuse all DCD donor lungs on EVLP [2, 97], whereas major US centers limit the indication for EVLP to only when the P/F ratio is less than $300 \mathrm{mmHg}$ in controlled DCD, having outcomes comparable to standard criteria brain-dead donors when $\mathrm{P} / \mathrm{F}$ ration is greater than $300[98,99 \cdot]$. DCD donor lungs with agonal time of more than $60 \mathrm{~min}$ might be good candidates for EVLP, while the Australian Collaborative Group considers the role of EVLP in DCD to be limited [100]. Regarding uncontrolled DCD, a Spanish group and few US centers have limited experience using EVLP to evaluate pulmonary function in this setting [101-104].

\section{EVLP for Clinical Use}

\section{Lund Protocol}

Since Steen and colleagues described the first clinical application for transplantation using donor lungs assessed with EVLP in 2000 [30], the Lund protocol has expanded mainly in Europe. This approach, like the Toronto Protocol described below, is utilized on stationary EVLP platforms that have no portability and are located at the transplant hospital [30]. Lungs are flushed in a standard fashion at procurement and transported utilizing standard, cold, static storage to the EVLP device. The Lund protocol is designed to mimic the physiological conditions that will occur after implantation. The LS1 system (XVIVO Perfusion Inc, Gothenburg, Sweden) is a commercially developed machine for clinical use with the Lund protocol (Table 1). The main goal of this protocol is to evaluate donor lungs that are initially rejected for lung transplantation using short perfusion time $(1.5 \mathrm{~h})$ [24, 30, 105]. This is because hydrostatic pressure and relatively high perfusate flow might induce mechanical injuries in the pulmonary 
Table 1 Three EVLP systems

\begin{tabular}{|c|c|c|c|}
\hline & Lund & Toronto & Organ Care System \\
\hline Perfusate & $\begin{array}{l}\text { STEEN with RBC, } \\
\text { hematocrit } 10-15 \%\end{array}$ & STEEN & $\begin{array}{l}\text { OCS solution with RBC, } \\
\text { hematocrit } 15-25 \%\end{array}$ \\
\hline Perfusate flow & $100 \%$ of $\mathrm{CO}$ & $40 \%$ of $\mathrm{CO}$ & $2-2.51 / \mathrm{min}$ \\
\hline Left atrium & Open & Closed $(3-5 \mathrm{mmHg})$ & Open \\
\hline Portability & No & No & Yes \\
\hline Perfusion time, $\mathrm{h}$ & $1.5 \mathrm{~h}$ & $4 \mathrm{~h}$ & Depends on distance \\
\hline Temperature, ${ }^{\circ} \mathrm{C}$ & 37 & 37 & 37 \\
\hline \multicolumn{4}{|l|}{ Rest ventilation settings } \\
\hline Regular tidal volume $(\mathrm{ml} / \mathrm{kg})$ & $6-8$ & 7 & 6 \\
\hline Regular frequency & 7 & 7 & 10 \\
\hline Regular PEEP $\left(\mathrm{cmH}_{2} \mathrm{O}\right)$ & 5 & 5 & 5 \\
\hline Regular $\mathrm{FiO}_{2}$ & 0.5 & 0.21 & 0.21 \\
\hline \multicolumn{4}{|l|}{ Ventilator setting at assessment } \\
\hline Tidal volume, $\mathrm{ml} / \mathrm{kg}$ & $6-8$ & 10 & 6 \\
\hline Frequency, breath/min & 7 & 10 & 10 \\
\hline PEEP, $\mathrm{cmH}_{2} \mathrm{O}$ & 5 & 5 & 5 \\
\hline $\mathrm{FiO}_{2}$ & $0.21,0.5,1.0$ & 1.0 & 0.21 \\
\hline
\end{tabular}

STEEN Steen solution, $\mathrm{RBC}$ red blood cells, $\mathrm{CO}$ cardiac output, $\mathrm{PEEP}$ positive end expiratory pressure, $\mathrm{FiO}_{2}$ fraction of inspired oxygen

vasculature [34]. Since the first lung transplant using EVLP was performed in 2000, several clinical trials have been launched to evaluate the safety of different EVLP protocols and devices (Table 2) [30].

In the UK, the DEVELOP-UK trial (ISRCTN44922411) was started in 2012 and included the five lung transplant centers in the UK. In a non-randomized study, they compared outcomes of transplantation of extended criteria donor lungs performing EVLP with modified Lund protocol using the Vivoline ${ }^{\circledR}$ LS1 device to standard donor lungs. The results of this trial showed lower estimated survival rates over 12 months in the EVLP group. In addition, patients in the EVLP group experienced higher rates of early graft dysfunction and need for ECMO. However, the early study termination had resulted in a small number of patients in the EVLP group which had limited the robustness of the conclusions [4]. This study included two EVLP protocols: Hybrid-EVLP protocol (open LA, an acellular perfusate and low flow rate of $40-60 \%$ of calculated cardiac output) in 22 cases and LundEVLP protocol (open LA, a cellular perfusate and full flow rate of $100 \%$ of calculated cardiac output) in 31 cases.

\section{Toronto Protocol}

Keshavjee and colleagues developed the Toronto EVLP protocol in 2008. This group focused mainly on preservation and treatment $[20,21]$. Their main target is a prolonged perfusion time of $4 \mathrm{~h}$ using acellular perfusate and a low perfusate flow strategy. Acellular perfusate is logistically simpler for clinical use and obviates the problem of hemolysis. Maximal perfusate flow is limited to $40 \%$ of estimated cardiac output. The goal of the low flow rate is the reduction of hydrostatic edema. The LA pressure is maintained positive. As described later, they reported that it was important to open the capillaries and postcapillary venules by controlling the LA pressure $[55,106]$.

In 2011, the Toronto team published the results of their first clinical trial (HELP trial NCT01190059). A non-randomized trial in which they compared the outcomes of transplantation of 20 high-risk donor lungs with a control group $(n=116)$. No significant differences were found in the incidence of primary graft dysfunction (PGD) or any of the secondary endpoints between the two groups. Therefore, they concluded that the results of transplanting these high-risk lungs are similar to transplanting conventionally selected lungs [2]. In 2011, XVIVO Perfusion started their NOVEL trial (NCT01365429) in the USA. It was a non-randomized trial comparing the outcomes of lung transplant using marginal donor lungs after performing EVLP with the XPS device and Steen solution to standard criteria donor lungs. In 2015, Lung Bioengineering Inc. started their first trial (NCT02234128) in which procured donor lungs were shipped to a dedicated EVLP facility to be perfused using the Toronto protocol. PGD 3 at 72-h posttransplant and 30-day patient survival were investigated as primary endpoint. Moreover, prolonged total preservation time of first CIT of $\leq 10 \mathrm{~h}$, EVLP time of $\leq 6 \mathrm{~h}$, and second CIT of $\leq 6 \mathrm{~h}$ was evaluated as secondary endpoint. Eight transplant centers were included in this trial. Recently, Lung Bioengineering Inc. launched their second trial (NCT03641677) aiming to increase lung transplant availability using EVLP at a dedicated facility. In a single-center randomized study in Vienna, standard criteria 


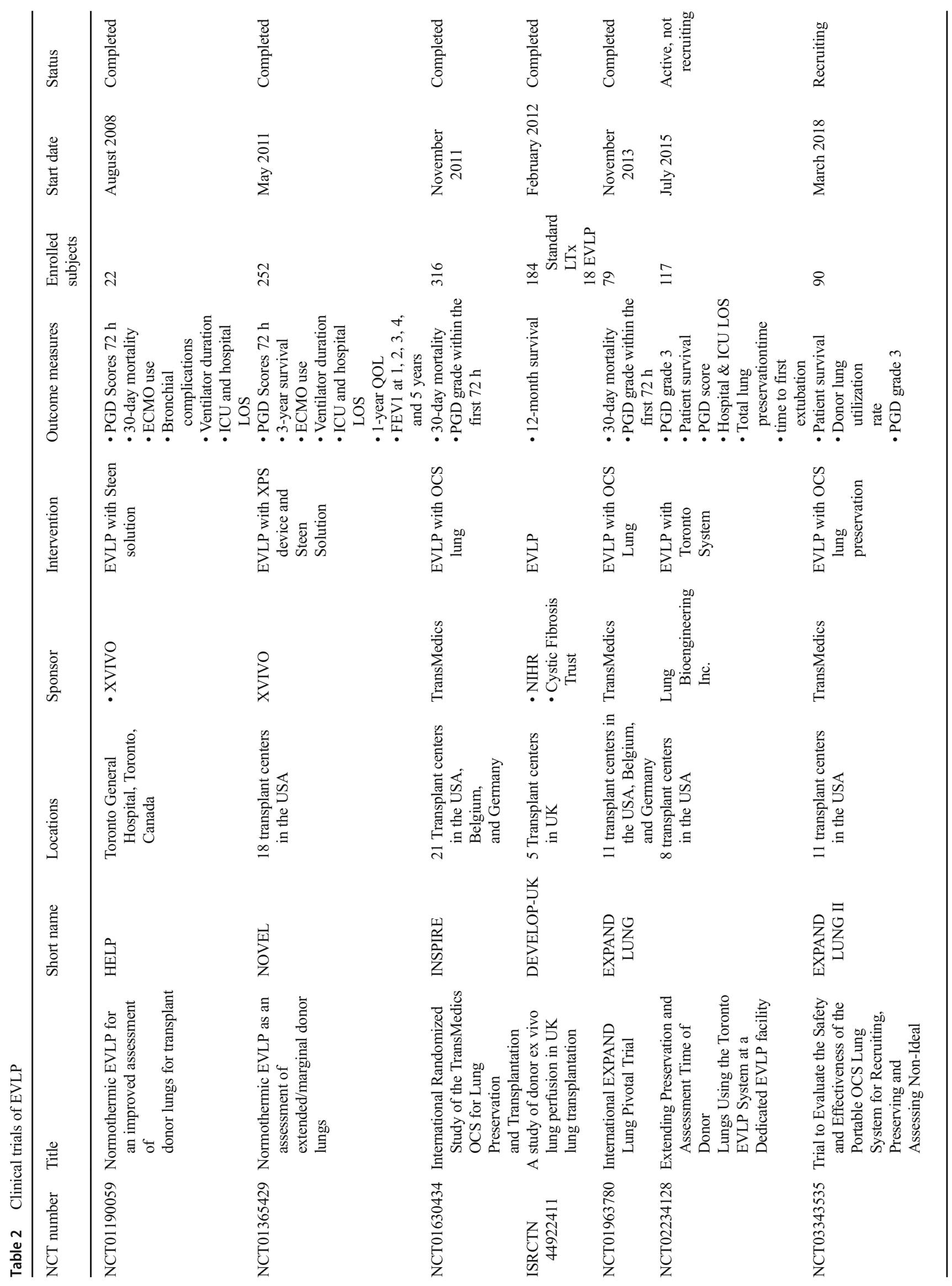


donor lungs were divided into two groups; straight transplantation and Toronto protocol EVLP. There was no significant difference in 30-day survival between the two groups. EVLP group demonstrated lower PGD grade $>1$ and lower postoperative ECMO rate without a significant difference [7••].

\section{Organ Care System}

In 2012, Warnecke and colleagues from Hanover reported a pilot study using the portable lung device Organ Care System (OCS, TransMedics, Andover, MA). In contrast to the Lund and Toronto protocol approaches, the OCS is taken to the donor hospital and, using donor or banked blood, lungs are transported on the device while being perfused with a bloodbased perfusate. The OCS device and protocol were developed and applied clinically with different ideas and goals than the above two protocols. In seeking regulatory approval, TransMedics' initial interest was transportation of standard lungs using the OCS device thus generating a shorter cold ischemic time than standard cold preservation strategies. The OCS protocol is characterized by cellular perfusate (STEEN Solution $^{\mathrm{TM}}+$ red blood cells), a relatively low perfusate flow (2.5 liters/min) and an open left atrium [38]. Currently, the STEEN Solution ${ }^{\mathrm{TM}}$ has been replaced by OCS solution, which is a low potassium dextran solution with added glucose and does not contain any albumin [46].

In 2011, TransMedics Inc. started their international, multicenter, randomized trial (INSPIRE trial NCT01630434). In this non-inferiority study, they compared EVLP with OCS perfusion device to cold preservation using standard criteria donor lungs. The results of this trial have proven the safety of the device with a lower incidence of lung graft-related serious adverse events in the OCS group compared with the control group. Additionally, the incidence of PGD 3 within the first 72-h post-transplant was found to be lower in the OCS group [3••]. In 2013, TransMedics Inc. started their second international, multicenter trial (EXPAND trial NCT01963780). This trial was a non-randomized study comparing outcomes of transplantation of extended criteria donor lungs with standard donor lungs. Recently, TransMedics Inc. has launched phase II of this trial (EXPAND II trial NCT03343535).

\section{Single-Center Outcomes Using EVLP}

Many transplant centers have performed EVLP in North America, Europe, Australia, and others and reports are currently limited to Canadian and European transplant facilities, as summarized in Table 3 [6, 35-38, 107-113]. Each center's report demonstrates that PGD 3 at $72 \mathrm{~h}$ was $2-28 \%$, and 1year survival rate was $67-93 \%$, and there was no difference compared with control lung transplantation group. In addition, the conversion rate, which is defined as transplanted 


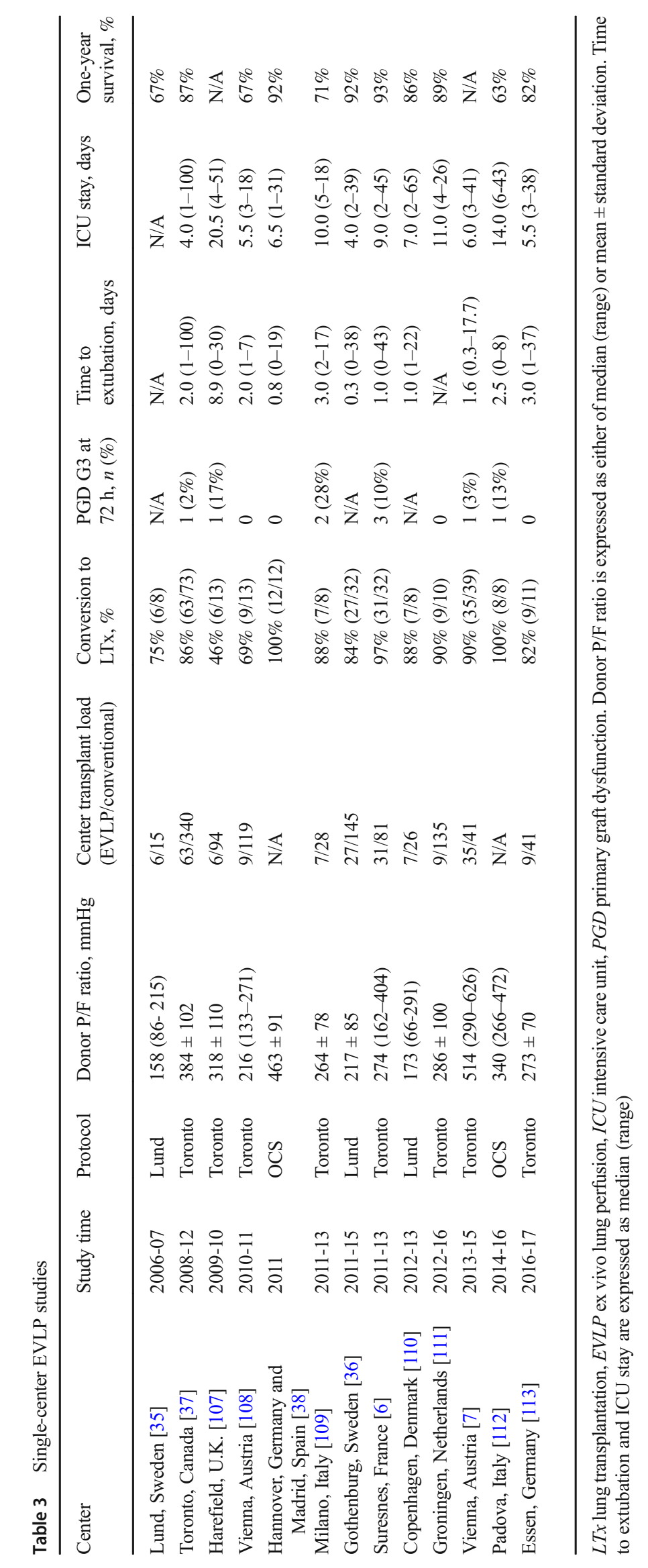


case/EVLP case, was 46-100\%, and the ratio of EVLP/all lung transplants was 6-38\%.

\section{Conclusions}

Clinical experience has demonstrated that EVLP is a useful tool to evaluate lungs and to salvage rejected donor lungs, and results in comparable outcomes to standard lung transplantation. Research has enriched knowledge in the evaluation and treatment of lungs utilizing several EVLP platforms. Further investigation on donor selection criteria for EVLP is warranted to enhance world-wide utilization of EVLP and to increase the donor lung pool.

\section{Compliance with Ethical Standards}

Conflict of Interest Kamal Ayyat has a patent (16/269,389) pending. Toshihiro Okamoto, Hiromichi Niikawa, Ichiro Sakanoue, Sayf Said, and Kenneth R. McCurry declare no conflict of interest.

Human and Animal Rights and Informed Consent This article does not contain any studies with human or animal subjects performed by any of the authors.

\section{References}

Papers of particular interest, published recently, have been highlighted as:

- Of importance

-• Of major importance

1. Valapour M, Skeans M, Smith J, Edwards L, Cherikh W, Uccellini K, et al. OPTN/SRTR 2015 annual data report: lung. Am J Transplant. 2017;17:357-424. https://doi.org/10.1111/ajt.14129.

2. Cypel M, Yeung JC, Liu M, Anraku M, Chen F, Karolak W, et al. Normothermic ex vivo lung perfusion in clinical lung transplantation. N Engl J Med. 2011;364(15):1431-40. https://doi.org/10. 1056/NEJMoa1014597.

3.• Warnecke G, Van Raemdonck D, Smith MA, Massard G, Kukreja $\mathrm{J}$, Rea F, et al. Normothermic ex-vivo preservation with the portable Organ Care System Lung device for bilateral lung transplantation (INSPIRE): a randomised, open-label, non-inferiority, phase 3 study. Lancet Respir Med. 2018;6(5):357-67. https:// doi.org/10.1016/s2213-2600(18)30136-x This study is a noninferiority, randomised, controlled, open-label, phase 3 trial, targeting double lung transplant recipient of stand criteria donor lungs [OCS $(n=151)$ vs. Control $(n=169)]$. The INSPIRE trial met its primary effectiveness and safety endpoints with no short-term survival benefit.

4. Fisher A, Andreasson A, Chrysos A, Lally J, Mamasoula C, Exley $\mathrm{C}$, et al. An observational study of donor ex vivo lung perfusion in UK lung transplantation: DEVELOP-UK. Health Technol Assess. 2016;20(85):1-276. https://doi.org/10.3310/hta20850.

5. Wallinder A, Riise GC, Ricksten S-E, Silverborn M, Dellgren G. Transplantation after ex vivo lung perfusion: a midterm follow-up. J Heart Lung Transplant. 2016;35(11):1303-10. https://doi.org/ 10.1016/j.healun.2016.05.021.
6. Sage E, Mussot S, Trebbia G, Puyo P, Stern M, Dartevelle P, et al. Lung transplantation from initially rejected donors after ex vivo lung reconditioning: the French experience. Eur J Cardiothorac Surg. 2014;46(5):794-9. https://doi.org/10.1093/ejcts/ezu245.

7.• Slama A, Schillab L, Barta M, Benedek A, Mitterbauer A, Hoetzenecker K, et al. Standard donor lung procurement with normothermic ex vivo lung perfusion: a prospective randomized clinical trial. J Heart Lung Transplant. 2017;36(7):744-53. https:// doi.org/10.1016/j.healun.2017.02.011 This study is a prospective single-center randomized clinical trial that compared patients $(n=39)$ who underwent transplant with EVLP-evaluated donor lungs with controls $(n=41)$ using standard criteria donor lungs. They conclude that EVLP can safely be used in standard donor lungs and allows clinicians to identify and to possibly exclude lungs with functional impairment.

8. Kerr J, Baker N, Bassett D, Fisher A. Effect of perfusate glucose concentration on rat lung glycolysis. Am J Physiol Endocrinol Metab. 1979;236(3):E229. https://doi.org/10.1152/ajpendo.1979. 236.3.E229.

9. Czartolomna J, Voelkel NF, Chang SW. Permeability characteristics of isolated perfused rat lungs. J Appl Physiol. 1991;70(4): 1854-60. https://doi.org/10.1152/jappl.1991.70.4.1854.

10. Niemeier R. The isolated perfused lung. Environ Health Perspect. 1984;56:35-41. https://doi.org/10.1289/ehp.845635.

11. Bassani GA, Lonati C, Brambilla D, Rapido F, Valenza F, Gatti S. Ex vivo lung perfusion in the rat: detailed procedure and videos. PLoS One. 2016;11(12):e0167898. https://doi.org/10.1371/ journal.pone.0167898.

12. Noda K, Shigemura N, Tanaka Y, Bhama JK, D'Cunha J, Luketich JD, et al. Successful prolonged ex vivo lung perfusion for graft preservation in rats. Eur J Cardiothorac Surg. 2014;45(3): e54-60. https://doi.org/10.1093/ejcts/ezt598.

13. DeCampos KN, Keshavjee S, Slutsky AS, Liu M. Alveolar recruitment prevents rapid-reperfusion-induced injury of lung transplants. J Heart Lung Transplant. 1999;18(11):1096-102. https:// doi.org/10.1016/S1053-2498(99)00082-0.

14. Fujinaga T, Nakamura T, Fukuse T, Chen F, Zhang J, Ueda S, et al. Isoflurane inhalation after circulatory arrest protects against warm ischemia reperfusion injury of the lungs. Transplantation. 2006;82(9):1168-74. https://doi.org/10.1097/01.tp.0000237207. 73439.2e.

15. Inokawa H, Sevala M, Funkhouser WK, Egan TM. Ex-vivo perfusion and ventilation of rat lungs from non-heart-beating donors before transplant. Ann Thorac Surg. 2006;82(4):1219-25. https:// doi.org/10.1016/j.athoracsur.2006.05.004.

16. Fukuse T, Albes JM, Takahashi Y, Brandes H, Hausen B, Schafers HJ. Influence of red blood cells on lung function in an ex vivo rat heart-lung model. J Surg Res. 1995;59(3):399-404. https://doi. org/10.1006/jsre.1995.1182.

17. Dong B, Stewart PW, Egan TM. Postmortem and ex vivo carbon monoxide ventilation reduces injury in rat lungs transplanted from non-heart-beating donors. J Thorac Cardiovasc Surg. 2013;146(2):429-36 e1. https://doi.org/10.1016/j.jtcvs.2012.11. 005.

18. Pierre AF, DeCampos KN, Liu M, Edwards V, Cutz E, Slutsky AS, et al. Rapid reperfusion causes stress failure in ischemic rat lungs. J Thorac Cardiovasc Surg. 1998;116(6):932-42. https://doi. org/10.1016/s0022-5223(98)70043-1.

19. Steen S, Liao Q, Wierup PN, Bolys R, Pierre L, Sjöberg T. Transplantation of lungs from non-heart-beating donors after functional assessment ex vivo. Ann Thorac Surg. 2003;76(1): 244-52. https://doi.org/10.1016/S0003-4975(03)00191-7.

20. Cypel M, Yeung JC, Hirayama S, Rubacha M, Fischer S, Anraku $\mathrm{M}$, et al. Technique for prolonged normothermic ex vivo lung 
perfusion. J Heart Lung Transplant. 2008;27(12):1319-25. https:// doi.org/10.1016/j.healun.2008.09.003.

21. Cypel M, Rubacha M, Yeung J, Hirayama S, Torbicki K, Madonik $\mathrm{M}$, et al. Normothermic ex vivo perfusion prevents lung injury compared to extended cold preservation for transplantation. Am J Transplant. 2009;9(10):2262-9. https://doi.org/10.1111/j.16006143.2009.02775.x.

22. Mulloy DP, Stone ML, Crosby IK, Lapar DJ, Sharma AK, Webb DV, et al. Ex vivo rehabilitation of non-heart-beating donor lungs in preclinical porcine model: delayed perfusion results in superior lung function. J Thorac Cardiovasc Surg. 2012;144(5):1208-15. https://doi.org/10.1016/j.jtcvs.2012.07.056.

23. U.S. Department of Health and Human Services Food and Drug Administration Center for Devise s and Radiological Health. Utilizing animal studies to evaluate organ preservation devices. https://www.fda.gov/media/107701/download. Accessed 21 Nov 2019.

24. Steen S, Ingemansson R, Eriksson L, Pierre L, Algotsson L, Wierup P, et al. First human transplantation of a nonacceptable donor lung after reconditioning ex vivo. Ann Thorac Surg. 2007;83(6):2191-4. https://doi.org/10.1016/j.athoracsur.2007.01. 033.

25. Okamoto T, Wheeler D, Liu Q, Quintini C, Hata JS, McCurry KR. Variability in pressure of arterial oxygen to fractional inspired oxygen concentration ratio during cellular ex vivo lung perfusion: implication for decision making. Transplantation. 2015;99(12): 2504-13. https://doi.org/10.1097/TP.0000000000000776.

26. Niikawa H, Okamoto T, Ayyat K, Itoda Y, Hata J, McCurry K. A Novel parameter of lung evaluation utilizing $\mathrm{PaO}_{2} / \mathrm{FiO}_{2}$ difference at the different $\mathrm{FiO}_{2}$ in ex vivo lung perfusion. $\mathrm{J}$ Heart Lung Transplant. 2018;37(4):S148.

27. Okamoto T, Wheeler D, Liu Q, Quintini C, Hata JS, McCurry KR. Correlation between $\mathrm{PaO} 2 / \mathrm{FiO} 2$ and airway and vascular parameters in the assessment of cellular ex vivo lung perfusion system. $\mathrm{J}$ Heart Lung Transplant. 2016;35(11):1330-6. https://doi.org/10. 1016/j.healun.2016.05.011.

28. Yeung JC, Cypel M, Machuca TN, Koike T, Cook DJ, Bonato R, et al. Physiologic assessment of the ex vivo donor lung for transplantation. J Heart Lung Transplant. 2012;31(10):1120-6. https:// doi.org/10.1016/j.healun.2012.08.016.

29. Zeriouh M, Sabashnikov A, Mohite PN, Zych B, Patil NP, GarciaSaez D, et al. Utilization of the organ care system for bilateral lung transplantation: preliminary results of a comparative study. Interact Cardiovasc Thorac Surg. 2016;23(3):351-7. https://doi. org/10.1093/icvts/ivw135.

30. Steen S, Sjoberg T, Pierre L, Liao Q, Eriksson L, Algotsson L. Transplantation of lungs from a non-heart-beating donor. Lancet. 2001;357(9259):825-9. https://doi.org/10.1016/S0140-6736(00) 04195-7.

31. Rega FR, Jannis NC, Verleden GM, Flameng WJ, Lerut TE, Van Raemdonck DE. Should we ventilate or cool the pulmonary graft inside the non-heart-beating donor? J Heart Lung Transplant. 2003;22(11):1226-33. https://doi.org/10.1016/S1053-2498(02) 01236-6.

32. Bennett DT, Reece TB, Smith PD, Grandhi MS, Jessica A, Justison GA, et al. Ex vivo lung perfusion allows successful transplantation of donor lungs from hanging victims. Ann Thorac Surg. 2014;98(3):1051-6. https://doi.org/10.1016/j.athoracsur.2014.04. 102.

33. Niikawa H, Okamoto T, Ayyat KS, Itoda Y, Hata JS, McCurry KR. Significant parameters in the evaluation of donor lungs in single-lung cellular ex vivo lung perfusion. Interact Cardiovasc Thorac Surg. 2018. https://doi.org/10.1093/icvts/ivy327.

34. Erasmus ME, Fernhout MH, Elstrodt JM, Rakhorst G. Normothermic ex vivo lung perfusion of non-heart-beating donor lungs in pigs: from pretransplant function analysis towards a 6-h machine preservation. Transpl Int. 2006;19(7):589-93. https:// doi.org/10.1111/j.1432-2277.2006.00318.x.

35. Ingemansson R, Eyjolfsson A, Mared L, Pierre L, Algotsson L, Ekmehag B, et al. Clinical transplantation of initially rejected donor lungs after reconditioning ex vivo. Ann Thorac Surg. 2009;87(1):255-60. https://doi.org/10.1016/j.athoracsur.2008.09. 049.

36. Wallinder A, Ricksten SE, Hansson C, Riise GC, Silverborn M, Liden $\mathrm{H}$, et al. Transplantation of initially rejected donor lungs after ex vivo lung perfusion. J Thorac Cardiovasc Surg. 2012;144(5):1222-8. https://doi.org/10.1016/j.jtcvs.2012.08.011.

37. Cypel M, Yeung JC, Machuca T, Chen M, Singer LG, Yasufuku $\mathrm{K}$, et al. Experience with the first 50 ex vivo lung perfusions in clinical transplantation. J Thorac Cardiovasc Surg. 2012;144(5): 1200-6. https://doi.org/10.1016/j.jtcvs.2012.08.009.

38. Warnecke G, Moradiellos J, Tudorache I, Kuhn C, Avsar M, Wiegmann B, et al. Normothermic perfusion of donor lungs for preservation and assessment with the Organ Care System Lung before bilateral transplantation: a pilot study of 12 patients. Lancet. 2012;380(9856):1851-8. https://doi.org/10.1016/S01406736(12)61344-0.

39.• Yeung JC, Krueger T, Yasufuku K, de Perrot M, Pierre AF, Waddell TK, et al. Outcomes after transplantation of lungs preserved for more than $12 \mathrm{~h}$ : a retrospective study. Lancet Respir Med. 2017;5(2):119-24. https://doi.org/10.1016/s2213-2600(16) 30323-x This study is the first publication retrospectively showing acceptable preservation time of perfused lungs in large volume cases.

40. Hsin MK, Iskender I, Nakajima D, Chen M, Kim H, Dos Santos $\mathrm{PR}$, et al. Extension of donor lung preservation with hypothermic storage after normothermic ex vivo lung perfusion. J Heart Lung Transplant. 2016;35(1):130-6. https://doi.org/10.1016/j.healun. 2015.05.017.

41. Cypel M, Yeung JC, Keshavjee S. Introducing the concept of semi-elective lung transplantation using ex vivo lung perfusion. Elsevier; 2018.

42. Loor G, Howard BT, Spratt JR, Mattison LM, PanoskaltsisMortari A, Brown RZ, et al. Prolonged EVLP using OCS lung: cellular and acellular perfusates. Transplantation. 2017;101(10): 2303-11. https://doi.org/10.1097/TP.0000000000001616.

43. Takahashi M, Cheung H, Chen M, Watanabe Y, Watanabe T, Harmantas $C$, et al. Twenty-four hour ex vivo lung perfusion: strategies to stabilize extended EVLP in a pig model. J Heart Lung Transplant. 2018;37(4):S223.

44. Sommer W, Salman J, Avsar M, Hoeffler K, Jansson K, Siemeni TN, et al. Prediction of transplant outcome after 24-hour ex vivo lung perfusion using the Organ Care System in a porcine lung transplantation model. Am J Transplant. 2019;19(2):345-55. https://doi.org/10.1111/ajt.15075 This study is the first report of successful $24 \mathrm{~h}$ of prolonged perfusion of porcine lungs in OCS, suggesting that STEEN solution plus red blood cells is favorable compared with other perfusates (STEEN solution only or STEEN solution plus low potassium dextran).

45. Cypel M, Liu M, Rubacha M, Yeung JC, Hirayama S, Anraku M, et al. Functional repair of human donor lungs by IL-10 gene therapy. Sci Transl Med. 2009;1(4):4ra9. https://doi.org/10.1126/ scitranslmed.3000266.

46. Andreasson A, Karamanou DM, Perry JD, Perry A, Özalp F, Butt $\mathrm{T}$, et al. The effect of ex vivo lung perfusion on microbial load in human donor lungs. J Heart Lung Transplant. 2014;33(9):910-6. https://doi.org/10.1093/ejcts/ezu228.

47. Nakajima D, Cypel M, Bonato R, Machuca TN, Iskender I, Hashimoto K, et al. Ex vivo perfusion treatment of infection in human donor lungs. Am J Transplant. 2016. https://doi.org/10. 1111/ajt.13562. 
48.• Galasso M, Feld JJ, Watanabe Y, Pipkin M, Summers C, Ali A, et al. Inactivating hepatitis $\mathrm{C}$ virus in donor lungs using light therapies during normothermic ex vivo lung perfusion. Nat Commun. 2019;10, 481 This study provides a novel technology of physical viral clearance using germicidal light-based therapy during EVLP.

49. Roman M, Gjorgjimajkoska O, Neil D, Nair S, Colah S, Parmar J, et al. Comparison between cellular and acellular perfusates for ex vivo lung perfusion in a porcine model. J Heart Lung Transplant. 2015;34(7):978-87. https://doi.org/10.1016/j.healun. 2015.03.023.

50. Becker S, Steinmeyer J, Avsar M, Höffler K, Salman J, Haverich A, et al. Evaluating acellular versus cellular perfusate composition during prolonged ex vivo lung perfusion after initial cold ischaemia for 24 hours. Transpl Int. 2016;29(1):88-97.

51. Steinmeyer J, Becker S, Avsar M, Salman J, Höffler K, Haverich A, et al. Cellular and acellular ex vivo lung perfusion preserve functional lung ultrastructure in a large animal model: a stereological study. Respir Res. 2018;19(1):238.

52. Nilsson T, Gielis JF, Slama A, Hasson C, Wallinder A, Ricksten SE, et al. Comparison of two strategies for ex vivo lung perfusion. J Heart Lung Transplant. 2018;37(2):292-8. https://doi.org/10. 1016/j.healun.2017.07.001 This study describes a comparison of two EVLP protocols using porcine lungs, and suggested the trend that lung edema and decreased lung compliance were more pronounced in acellular closed left atrium group compared with cellular open left atrium group.

53. Okamoto T. Wheeler D. Farver CF; McCurry KR. Transplant suitability of rejected human donor lungs with prolonged cold ischemia time in low flow acellular and high flow cellular ex vivo lung perfusion systems. Transplantation: 2019; 103(9): 1799-1808 https://doi.org/10.1097/tp.0000000000002667. This study demonstrates that the potential for reconditioning rejected human lungs with CIT greater than 8 hours (mean 13.8 hours) is limited due to severe ischemia reperfusion injury in two EVLP protocols.

54. Peták F, Habre W, Hantos Z, Sly PD, Morel DR. Effects of pulmonary vascular pressures and flow on airway and parenchymal mechanics in isolated rat lungs. J Appl Physiol. 2002;92(1):169 78. https://doi.org/10.1152/jappl.2002.92.1.169.

55. Linacre V, Cypel M, Machuca T, Nakajima D, Hashimoto K, Zamel R, et al. Importance of left atrial pressure during ex vivo lung perfusion. J Heart Lung Transplant. 2016;35(6):808-14. https://doi.org/10.1016/j.healun.2016.02.008.

56. Slutsky AS, Ranieri VM. Ventilator-induced lung injury. N Engl J Med. 2013;369(22):2126-36. https://doi.org/10.1056/ NEJMra1208707.

57. Terragni PP, Fanelli V, Boffini M, Filippini C, Cappello P, Ricci D, et al. Ventilatory management during normothermic ex vivo lung perfusion: effects on clinical outcomes. Transplantation. 2016;100(5):1128-35. https://doi.org/10.1097/TP. 0000000000000929.

58. Mehaffey JH, Charles EJ, Sharma AK, Salmon M, Money D, Schubert S, et al. Airway pressure release ventilation during ex vivo lung perfusion attenuates injury. J Thorac Cardiovasc Surg. 2017;153(1):197-204. https://doi.org/10.1016/j.jtcvs.2016. 09.029 This study provide an evidence that airway pressure release ventilation during EVLP might be protective, compared with the current standard lung protective ventilation setting.

59. Aboelnazar NS, Himmat S, Hatami S, White CW, Burhani MS, Dromparis P, et al. Negative pressure ventilation decreases inflammation and lung edema during normothermic ex-vivo lung perfusion. J Heart Lung Transplant. 2018;37(4):520-30. https://doi.org/ 10.1016/j.healun.2017.09.007.
60. Noda K, Tane S, Haam SJ, Hayanga AJ, D'Cunha J, Luketich JD, et al. Optimal ex vivo lung perfusion techniques with oxygenated perfusate. J Heart Lung Transplant. 2017;36(4):466-74. https:// doi.org/10.1016/j.healun.2016.10.014.

61. Luc JG, Aboelnazar NS, Himmat S, Hatami S, Haromy A, Matsumura N, et al. A leukocyte filter does not provide further benefit during ex vivo lung perfusion. ASAIO J. 2017;63(5):6728. https://doi.org/10.1097/MAT.0000000000000550.

62. Noda K, Tane S, Haam SJ, D'cunha J, Hayanga AJ, Luketich JD, et al. Targeting circulating leukocytes and pyroptosis during ex vivo lung perfusion improves lung preservation. Transplantation. 2017;101(12):2841-9. https://doi.org/10.1097/ TP.0000000000001798.

63. Schumer EM, Zoeller KA, Linsky PL, Monreal G, Choi Y, Giridharan GA, et al. Feasibility study of pulsatile left ventricular assist device for prolonged ex vivo lung perfusion. Ann Thorac Surg. 2015;99(6):1961-8. https://doi.org/10.1016/j.athoracsur. 2015.02.087.

64. Bloomfield R, Noble DW, Sudlow A. Prone position for acute respiratory failure in adults. Cochrane Database Syst Rev. 2015;11:CD008095. https://doi.org/10.1002/14651858. CD008095.pub2.

65. Nikawa H, Okamoto T, Ayyat KS, Itoda Y, Farver CF, McCurry $\mathrm{KR}$. The protective effect of prone lung position on ischemiareperfusion injury and lung function in an ex vivo porcine lung model. J Thorac Cardiovasc Surg. 2019;157(1):425-33. https:// doi.org/10.1016/j.jtcvs.2018.08.101 This study demonstrate that prone position of porcine lungs in EVLP was associated with better oxygenation and lower lung weight ratio and lower IL-1 beta level, compared with the supine positioned lungs.

66. Costa J, Sreekanth S, Kossar A, Raza K, Lederer DJ, Robbins H, et al. Donor lung assessment using selective pulmonary vein gases. Eur J Cardiothorac Surg. 2016;50(5):826-31. https://doi.org/ 10.1093/ejcts/ezw179.

67. Venkateswaran RV, Dronavalli V, Patchell V, Wilson I, Mascaro J, Thompson R, et al. Measurement of extravascular lung water following human brain death: implications for lung donor assessment and transplantation. Eur J Cardiothorac Surg. 2012;43(6):122732.

68. Trebbia G, Sage E, Le Guen M, Roux A, Soummer A, Puyo P, et al. Assessment of lung edema during ex-vivo lung perfusion by single transpulmonary thermodilution: A preliminary study in humans. J Heart Lung Transplant. 2018. https://doi.org/10.1016/ j.healun.2018.09.019.

69. Ayyat K, Okamoto T, Niikawa H, Itoda Y, Dugar S Q, Latifi S, et al. DireCt lung ultrasound evaluation (CLUE): a novel technique for monitoring extravascular lung water in donor lungs. $\mathrm{J}$ Heart Lung Transplant. 2019; 38(7): 757-66.

70. Molina DK, DiMaio VJ. Normal organ weights in men: part IIthe brain, lungs, liver, spleen, and kidneys. Am J Forensic Med Pathol. 2012;33(4):368-72. https://doi.org/10.1097/PAF. 0b013e31823d29ad.

71. Molina DK, DiMaio VJ. Normal organ weights in women: part II - the brain, lungs, liver, spleen, and kidneys. Am J Forensic Med Pathol. 2015;36(3):182-7. https://doi.org/10.1097/PAF. 0000000000000175 .

72. Tagami T, Kushimoto S, Yamamoto Y, Atsumi T, Tosa R, Matsuda $\mathrm{K}$, et al. Validation of extravascular lung water measurement by single transpulmonary thermodilution: human autopsy study. Crit Care. 2010;14(5):R162.

73. Andreasson AS, Borthwick LA, Gillespie C, Jiwa K, Scott J, Henderson $P$, et al. The role of interleukin- $1 \beta$ as a predictive biomarker and potential therapeutic target during clinical ex vivo lung perfusion. J Heart Lung Transplant. 2017;36(9):985-95. https://doi.org/10.1016/j.healun.2017.05.012. 
74. Machuca TN, Cypel M, Yeung JC, Bonato R, Zamel R, Chen M, et al. Protein expression profiling predicts graft performance in clinical ex vivo lung perfusion. Ann Surg. 2015;261(3):591-7. https://doi.org/10.1097/SLA.0000000000000974.

75. Hsin MK, Zamel R, Cypel M, Wishart D, Han B, Keshavjee S, et al. Metabolic profile of ex vivo lung perfusate yields biomarkers for lung transplant outcomes. Ann Surg. 2018;267(1):196-7. https://doi.org/10.1097/SLA.0000000000002016.

76. Wallinder A, Hansson C, Dellgren G. Hemoconcentration in ex vivo lung perfusion: a case report of a novel technique used in clinical lung transplantation. J Thorac Cardiovasc Surg. 2013;145(6):e76-7. https://doi.org/10.1016/j.jtcvs.2013.03.001.

77. Nilsson T, Hansson C, Wallinder A, Malm CJ, Silverborn M, Ricksten SE, et al. Hemofiltration in ex vivo lung perfusion-a study in experimentally induced pulmonary edema. J Thorac Cardiovasc Surg. 2016;151(2):570-5 e1. https://doi.org/10.1016/ j.jtcvs.2015.06.046.

78. Khalifé-Hocquemiller T, Sage E, Dorfmuller P, Mussot S, Le Houérou D, Eddahibi S, et al. Exogenous surfactant attenuates lung injury from gastric-acid aspiration during ex vivo reconditioning in pigs. Transplantation. 2014;97(4):413-8. https://doi.org/10.1097/01.TP.0000441320.10787.c5.

79. Inci I, Hillinger S, Arni S, Kaplan T, Inci D, Weder W. Reconditioning of an injured lung graft with intrabronchial surfactant instillation in an ex vivo lung perfusion system followed by transplantation. J Surg Res. 2013;184(2):1143-9. https://doi. org/10.1016/j.jss.2013.04.043.

80. Nakajima D, Liu M, Ohsumi A, Kalaf R, Iskender I, Hsin M, et al. Lung lavage and surfactant replacement during ex vivo lung perfusion for treatment of gastric acid aspiration-induced donor lung injury. J Heart Lung Transplant. 2017;36(5):577-85. https://doi. org/10.1016/j.healun.2016.11.010.

81. Huang C-S, Kawamura T, Toyoda Y, Nakao A. Recent advances in hydrogen research as a therapeutic medical gas. Free Radic Res. 2010;44(9):971-82. https://doi.org/10.3109/10715762.2010. 500328 .

82. Noda K, Shigemura N, Tanaka Y, Bhama J, D'cunha J, Kobayashi $\mathrm{H}$, et al. Hydrogen preconditioning during ex vivo lung perfusion improves the quality of lung grafts in rats. Transplantation. 2014;98(5):499-506.

83. Haam S, Lee S, Paik HC, Park MS, Song JH, Lim BJ, et al. The effects of hydrogen gas inhalation during ex vivo lung perfusion on donor lungs obtained after cardiac death. Eur J Cardiothorac Surg. 2015;48(4):542-7. https://doi.org/10.1093/ejcts/ezv057.

84. Ware LB, Fang X, Wang Y, Babcock WD, Jones K, Matthay MA. High prevalence of pulmonary arterial thrombi in donor lungs rejected for transplantation. J Heart Lung Transplant. 2005;24(10):1650-6. https://doi.org/10.1016/j.healun.2004.11. 011.

85. Oto T, Rabinov M, Griffiths AP, Whitford H, Levvey BJ, Esmore DS, et al. Unexpected donor pulmonary embolism affects early outcomes after lung transplantation: a major mechanism of primary graft failure? J Thorac Cardiovasc Surg. 2005;130(5):1446. e19. https://doi.org/10.1016/j.jtcvs.2005.07.025.

86. Brown CR, Brozzi NA, Vakil N, Shafii AE, Murthy SC, Pettersson GB, et al. Donor lungs with pulmonary embolism evaluated with ex vivo lung perfusion. ASAIO J. 2012;58(4):432-4. https://doi.org/10.1097/MAT.0b013e318251cde4.

87. Inci I, Zhai W, Arni S, Inci D, Hillinger S, Lardinois D, et al. Fibrinolytic treatment improves the quality of lungs retrieved from non-heart-beating donors. J Heart Lung Transplant. 2007;26(10): 1054-60. https://doi.org/10.1016/j.healun.2007.07.033.

88. Inci I, Yamada Y, Hillinger S, Jungraithmayr W, Trinkwitz M, Weder W. Successful lung transplantation after donor lung reconditioning with urokinase in ex vivo lung perfusion system.
Ann Thorac Surg. 2014;98(5):1837-8. https://doi.org/10.1016/j. athoracsur.2014.01.076.

89. Motoyama H, Chen F, Hijiya K, Kondo T, Ohsumi A, Yamada T, et al. Plasmin administration during ex vivo lung perfusion ameliorates lung ischemia-reperfusion injury. J Heart Lung Transplant. 2014;33(10):1093-9. https://doi.org/10.1016/j. healun.2014.06.004.

90. Machuca TN, Hsin MK, Ott HC, Chen M, Hwang DM, Cypel M, et al. Injury-specific ex vivo treatment of the donor lung: pulmonary thrombolysis followed by successful lung transplantation. Am J Respir Crit Care Med. 2013;188(7):878-80. https://doi. org/10.1164/rccm.201302-0368LE.

91. Harada M, Oto T, Otani S, Miyoshi K, Okada M, Iga N, et al. A neutrophil elastase inhibitor improves lung function during ex vivo lung perfusion. Gen Thorac Cardiovasc Surg. 2015;63(12):645-51.

92. Lin H, Chen M, Tian F, Tikkanen J, Ding L, Andrew Cheung HY, et al. $\alpha 1$-Anti-trypsin improves function of porcine donor lungs during ex-vivo lung perfusion. J Heart Lung Transplant. 2018;37(5):656-66. https://doi.org/10.1016/j.healun.2017.09. 019.

93. Charles EJ, Mehaffey JH, Sharma AK, Zhao Y, Stoler MH, Isbell $\mathrm{JM}$, et al. Lungs donated after circulatory death and prolonged warm ischemia are transplanted successfully after enhanced ex vivo lung perfusion using adenosine $\mathrm{A} 2 \mathrm{~B}$ receptor antagonism. J Thorac Cardiovasc Surg. 2017;154(5):1811-20. https://doi.org/ 10.1016/j.jtcvs.2017.02.072.

94. Okamoto T, Niikawa H, Wheeler D, Ayyat K, Soliman B, Itoda Y, et al. Selective recruitment of large lower lobe atelectasis on donor back table in rejected donor lungs. Transpl Direct. 2019;5(5):e453 In Press.

95. Fukuse T, Hirata T, Nakamura T, Kawashima M, Hitomi S, Wada $\mathrm{H}$. Influence of deflated and anaerobic conditions during cold storage on rat lungs. Am J Respir Crit Care Med. 1999;160(2): 621-7. https://doi.org/10.1164/ajrccm.160.2.9809023.

96.• Levvey B, Keshavjee S, Cypel M, Robinson A, Erasmus M, Glanville A, et al. Influence of lung donor agonal and warm ischemic times on early mortality: analyses from the ISHLT DCD Lung Transplant Registry. J Heart Lung Transplant. 2019;38(1): 26-34. https://doi.org/10.1016/j.healun.2018.08.006 This study is the largest retrospective study $(n=507)$ of outcomes of category III DCD donors using ISHLT DCD Lung Transplant Registry. They conclude that day 30 and 1-year survival were not statistically different according to agonal or warm ischemic time category.

97. Machuca T, Mercier O, Collaud S, Tikkanen J, Krueger T, Yeung $\mathrm{J}$, et al. Lung transplantation with donation after circulatory determination of death donors and the impact of ex vivo lung perfusion. Am J Transplant. 2015;15(4):993-1002. https://doi.org/10.1111/ ajt.13124.

98. Mason DP, Brown CR, Murthy SC, Vakil N, Lyon C, Budev MM, et al. Growing single-center experience with lung transplantation using donation after cardiac death. Ann Thorac Surg. 2012;94(2): 406-12. https://doi.org/10.1016/j.athoracsur.2012.03.059.

99. Costa J, Shah L, Robbins H, Raza K, Sreekandth S, Arcasoy S, et al. Use of lung allografts from donation after cardiac death donors: a single-center experience. Ann Thorac Surg. 2018;105(1):271-8. https://doi.org/10.1016/j.athoracsur.2017.07. 023 This study is a recent single-center retrospective study ( $n$ = 73) of category III DCD donor lungs on 2007-2016. Recipients from DCD donors $(n=46$, dry run rate: $40 \%$ ) shows equivalent PGD rate at $72 \mathrm{~h}$ and 1- and 3-year survival compared with controls.

100. Levvey B, Harkess M, Hopkins P, Chambers D, Merry C, Glanville A, et al. Excellent clinical outcomes from a national donation-after-determination-of-cardiac-death lung transplant 
collaborative. Am J Transplant. 2012;12(9):2406-13. https://doi. org/10.1111/j.1600-6143.2012.04193.x.

101. Gámez $\mathrm{P}$, Córdoba M, Ussetti $\mathrm{P}$, Carreño MAC, Alfageme F, Madrigal L, et al. Lung transplantation from out-of-hospital nonheart-beating lung donors. one-year experience and results. $\mathrm{J}$ Heart Lung Transplant. 2005;24(8):1098-102. https://doi.org/10. 1016/j.healun.2004.06.002.

102. Suzuki Y, Tiwari J, Lee J, Diamond J, Blumenthal N, Carney K, et al. Should we reconsider lung transplantation through uncontrolled donation after circulatory death? Am J Transplant. 2014;14(4):966-71. https://doi.org/10.1111/ajt.12633.

103. Egan T, Requard J III. Uncontrolled donation after circulatory determination of death donors (uDCDDs) as a source of lungs for transplant. Am J Transplant. 2015;15(8):2031-6. https://doi. org/10.1111/ajt.13246.

104. Valenza F, Citerio G, Palleschi A, Vargiolu A, Fakhr BS, Confalonieri A, et al. Successful transplantation of lungs from an uncontrolled donor after circulatory death preserved in situ by alveolar recruitment maneuvers and assessed by ex vivo lung perfusion. Am J Transplant. 2016;16(4):1312-8. https://doi.org/ 10.1111/ajt.13612.

105. Lindstedt S, Hlebowicz J, Koul B, Wierup P, Sjögren J, Gustafsson R, et al. Comparative outcome of double lung transplantation using conventional donor lungs and non-acceptable donor lungs reconditioned ex vivo. Interact Cardiovasc Thorac Surg. 2011;12(2):162-5. https://doi.org/10.1510/icvts.2010. 244830.

106. Alessandrini F, D'Armini AM, Roberts CS, Reddick RL, Egan TM. When does the lung die? II. Ultrastructural evidence of pulmonary viability after "death". J Heart Lung Transplant. 1994;13(5):748-57.

107. Zych B, Popov AF, Stavri G, Bashford A, Bahrami T, Amrani M, et al. Early outcomes of bilateral sequential single lung transplantation after ex-vivo lung evaluation and reconditioning. J Heart Lung Transplant. 2012;31(3):274-81. https://doi.org/10. 1016/j.healun.2011.10.008.

108. Aigner C, Slama A, Hötzenecker K, Scheed A, Urbanek B, Schmid W, et al. Clinical ex vivo lung perfusion - pushing the limits. Am J Transplant. 2012;12(7):1839-47. https://doi.org/10. 1111/j.1600-6143.2012.04027.x.

109. Valenza F, Rosso L, Coppola S, Froio S, Palleschi A, Tosi D, et al. Ex vivo lung perfusion to improve donor lung function and increase the number of organs available for transplantation. Transpl Int. 2014;27(6):553-61. https://doi.org/10.1111/tri.12295.

110. Henriksen I, Møller-Sørensen H, Møller CH, Zemtsovski M, Nilsson JC, Seidelin CT, et al. First Danish experience with ex vivo lung perfusion of donor lungs before transplantation. Danish Med J. 2014;61(3):A4809.

111. Zhang ZL, van Suylen V, van Zanden JE, Van De Wauwer C, Verschuuren EA, van der Bij W, et al. First experience with ex vivo lung perfusion for initially discarded donor lungs in the Netherlands: a single-centre study. Eur J Cardiothorac Surg. 2018;55(5):920-6. https://doi.org/10.1093/ejcts/ezy373.

112. Schiavon M, Faggi G, Rebusso A, Lunardi F, Comacchio G, Di Gregorio G, et al. Extended criteria donor lung reconditioning with the organ care system lung: a single institution experience. Transpl Int. 2019;32(2):131-40. https://doi.org/10.1111/tri.13365.

113. Koch A, Pizanis N, Olbertz C, Abou-Issa O, Taube C, Slama A, et al. One-year experience with ex vivo lung perfusion: preliminary results from a single center. Int J Artif Organs. 2018;41(8): 460-6. https://doi.org/10.1177/0391398818783391.

Publisher's Note Springer Nature remains neutral with regard to jurisdictional claims in published maps and institutional affiliations. 